\title{
Emigração e exílio, novas abordagens nos estudos migratórios: considerações sobre o artigo de Sylvie Aprile
}

\author{
Érica Sarmiento* \\ Universidade do Estado do Rio de Janeiro \\ Rio de Janeiro - Rio de Janeiro - Brasil
}

\section{Resumo}

A partir da discussão das reflexões encaminhadas por Sylvie Aprile em seu artigo intitulado Exílios (s) e migrações(s) Transatlânticas: histórias entrelaçadas, historiografias paralelas, desenvolvemos algumas considerações acerca da problemática dos exílios e das migrações. Realizamos uma sucinta análise teórica, abordando os estudos macros e micro analíticos, a metodologia quantitativa e qualitativa, e a comparativa, com o intuito de dialogar com os três estudos de casos apresentados por Sylvie Aprile. O objetivo não é encontrar respostas conclusivas, mas buscar, nas novas metodologias e abordagens, diferentes interpretações e novos interrogantes para a análise das trajetórias e das experiências migratórias.

\section{Pallaviras chave}

migrações- exílios- estudos migratórios- historiografia

Professora Adjunta na Universidade do Estado do Rio de Janeiro; professora titular do Programa de Mestrado em História da Universidade Salgado de Oliveira. Coordenadora do Laboratório de Estudos de Imigração (Labimi/UERJ) e do Laboratório de Imigração e Estudos Ibéricos (UNIVERSO). É pesquisadora Jovem Cientista Nosso Estado da FAPERJ. E-mail: erisarmiento@gmail.com 


\section{Abstract}

From the discussion of the reflections forwarded by Sylvie Aprile in his article entitled Transatlantic Exiles and migrations: intertwined histories, parallel historiographies, we have developed some considerations about the problem of exiles and migrations. We present a brief theoretical analysis, addressing the macros and microanalytical studies, the quantitative and qualitative methodology, and the comparative one, with the intention of dialoguing with the three case studies presented by Sylvie Aprile. The objective is not to find conclusive answers, but to seek, in the new methodologies and approaches, different interpretations and new questions for the analysis of trajectories and migratory experiences.

\section{Key words}

migrations- exiles- migratory studies- historiography 
O artigo de Sylvie Aprile, intitulado Exílios (s) e migrações(s) Transatlânticas: histórias entrelaçadas, historiografias paralelas nos oferece um conjunto de questões e reflexões acerca da imigração e exílio, temas que, como a própria autora sinaliza, encontram-se na pauta da atualidade europeia, em meio a uma situação dramática e dolorosa que envolve os novos deslocamentos humanos.

$\mathrm{O}$ texto se apoia basicamente em duas questões principais, que destacaremos de forma sucinta. A primeira diz respeito à relação que se estabelece na historiografia entre imigração e exílio e as suas variáveis. A segunda relaciona-se aos motivos inerentes aos respectivos processos: a imigração vinculada às questões econômicas; e o exílio às questões políticas. Essa seria a linha de interpretação dominante na historiografia sobre imigração que a autora pretende problematizar. A argumentação busca desconstruir a distinção radical entre imigração e exílio, indicando a articulação entre motivações políticas e econômicas nas experiências de estudos de caso, de três franceses que migraram para a América no século XIX por razões políticas. Os dois primeiros casos, em decorrência do golpe de 1851 de Napoleão III e o terceiro, de uma personagem, feminina, uma mulher que emigra para a América com o intuito de fugir às perseguições sofridas pelos participantes da Comuna de Paris em 1871. A ênfase da análise recai sobre as trocas culturais entre origens e destinos e vice-versa. Os movimentos migratórios atuaram, como indicam as experiências dos três franceses analisados pela autora, como propiciadores dessas trocas. A trajetória individual dos personagens estudados revelaria, dessa forma, o equívoco em separar, nos processos históricos, as experiências de imigração e exílio, assim como seria equivocado distinguir, nos processos atuais, a condição de imigrante da de refugiado.

O texto apresenta um rico campo de reflexões e novas questões para as migrações e exílios, como pode ser o uso da metolodogia comparada, as teorias migratórias tradicionais, a problemática das fontes e o significado dos conceitos. Cabe ressaltar uma afirmação muito importante realizada pela autora, logo ao iniciar o artigo, que é a de que "O historiador do século XIX como eu, como você, não pode ser insensível ao presente". E, partindo dessa afirmação, e do fato das 
migrações constituírem-se como fenômenos cíclicos, é que a historiografia vem repensando os conceitos e suas novas abordagens. Quando os conceitos se apresentam como ininteligíveis no âmbito de redes conceituais mais gerais, com o surgimento de novos sentidos adequados às novas realidades, tona-se necessário buscar as limitações e os enquadramentos entre o passado e o presente, e pensar na longa duração, redefinindo metodologias e escalas de análises para os processos migratórios. Sylvie Aprile, em seu texto, em relação aos deslocamentos do século XIX, é consciente de que sua sociedade, a francesa, apresenta-se como receptora de exílios, de emigração e de refúgios. Não obstante, a autora, em sua larga trajetória correspondente a 15 anos de estudos sobre o exílio, não se dedicou à temática dos exilados europeus na França (vista como uma terra de acolhida), mas optou por analisar a emigração francesa no século XIX, em especial aqueles casos que se dirigiram para a América. Seguindo essa escolha, Sylvie Aprile norteou a sua abordagem para um pensamento mais transnacional e global, a partir de como a experiência migratória francesa entrou em contato com outras culturas. Segundo a autora, as pesquisas tenderam a se concentrar no protagonismo da França como país de acolhida, como por exemplo, a análise dos exiliados republicanos espanhóis do período da Guerra Civil e da ditadura franquista. Em contrapartida, foram escassas as pesquisas vinculadas aos deslocamentos de franceses, pois a contribuição foi considerada de menor importância quantitativamente para a história global da migração voluntária ou forçada.

O livro de Hernán Otero, intitulado Historia de los franceses en la Argentina, é uma das obras de referência para os estudos da presença gala no país austral desde o início dos fluxos, na década de 1830, até meados do século XX. Otero percorre os tópicos clássicos dos estudos migratórios, sinalizando as causas da emigração no país de origem, as formas de chegada, a inserção econômica e espacial, a formação dos matrimônios, o retorno, a mobilidade social, a liturgia patriótica, a adaptação linguística e a criação de associações, escolas e imprensa étnica. A particularidade da obra de Otero encontra-se no fato de sua pesquisa entrelaçar as relações da coletividade com as instituições diplomáticas e a forma como estas tiveram um impacto importante 
tanto nas ações comunitárias como na integração dos imigrantes e de seus filhos na sociedade argentina. $\mathrm{O}$ autor afirma que a presença francesa passou de 5000 pessoas no ano de 1836 a 12 mil em 1842, e a mediados da década de 1854 atingiu o número aproximado de 25 mil emigrantes franceses na Argentina. É importante frisar que a Argentina, nesse período do século XIX, viveu o fenômeno da francofobia. As invasões francesas no período da pré-independência e os bloqueios anglo-franceses que aconteceram nos interregnos de março de 1838 a outubro de 1940 e em setembro de 1945 a julho de 1847 provocou o rechaço da sociedade argentina em relação à emigração gala. Otero destaca que a presença francesa foi mais numerosa que a dos ingleses e irlandeses, o que permite enfatizar o lugar central, apesar da francofobia, que ocuparam as condições socioeconômicas dos países de origem e de destino em relação às políticas migratórias ${ }^{1}$.

Um claro exemplo disso é a trajetória da personagem feminina analisada por Sylvie Aprile, a da costureira Herminie Cadolle, que se mudou para Paris no ano de 1860, acompanhada do marido. Ela se envolveu nos acontecimentos da Comuna de Paris, em 1871, e se tornou amiga de Louise Michel, uma das grandes figuras femininas do movimento anarquista francês. No fim da insurreição ela foi presa por seis meses em Rouen. Com a morte do marido, Herminie Cardolle decide deixar a França e parte para Buenos Aires em 1887. Na cidade porteña, ela abre um comércio de lingerie e torna-se uma comerciante empreendedora e de sucesso, criando novas peças de corselete e dividindo o antigo "corpinho", peça fundamental no guarda-roupa feminino da época, em duas peças íntimas. A partir de sua nova invenção, Cardolle participa de feiras internacionais e recebe prêmios. Sua criatividade e engenho vão além da confecção de roupas íntimas, ela cria um novo método de venda para a época: a venda por catálogo. No auge do seu sucesso, exportou mercadorias para diferentes cidades como Londres, Nova York e São Petersburgo. A trajetória dessa personagem e a sua carreira de comerciante de prestígio estão vinculadas não só ao seu

\footnotetext{
1 OTERO, Hernán. História de los franceses en la Argentina. Buenos Aires: Editorial Biblos, 2012, p. 112.
} 
esforço pessoal e sua criatividade, mas também às características de uma cidade como Buenos Aires no alvorecer do século XX, receptora de emigração europeia e considerada, para muitos, a "Paris da América". Estamos diante de um exemplo de uma emigrante exilada, um caso excepcional no universo feminino no século XIX, que obteve a sua ascensão econômica no auge do período da emigração de massas da Europa para a América. Histórias que, segundo Aprile, são difíceis de relatar pela invisibilidade dessas mulheres e pelo silêncio das fontes históricas em relação à presença feminina.

A metodologia quantitativa é uma das problemáticas que norteiam o artigo de Sylvie Aprile. Segundo a autora, raro são os autores que abordam da mesma forma os diferentes tipos de migração. Os trabalhos são orientados mais facilmente para as migrações de massa ou aquelas quantitativamente mais frágeis, como o caso dos exilados políticos. É o caso da obra de Philippe Rygiel, intitulada Tempo das migrações brancas ${ }^{2}$, analisada por Aprile. Em relação às metodologias aplicadas nos estudos migratórios, nas últimas décadas, as pesquisas sobre as migrações internacionais experimentaram um notável impulso. De forma geral, houve uma crise dos modelos de análises macrossociais (as diferentes variantes de marxismos, os funcionalismos etc.) e um avanço no surgimento de novas análises, voltadas para a história social, a demografia e a antropologia histórica. Este fenómeno foi acompanhado pela ampliação de temáticas e pela renovação de metodologias aplicadas, que possibilitaram a passagem do método puramente quantitativo para outros que introduziram as perspectivas analíticas de tipo qualitativo. O método qualitativo permitiu a utilização de fontes antes subestimadas pela historiografia mais tradicional, como as correspondências, as fotografias, entrevistas, etc ${ }^{3}$.

2 Philippe Rygiel, Le temps des migrations blanches: migrer en Occident (1840-1940). Paris: Publibook, 2010.

3 Como referências podemos citar as obras de DEVOTO, Fernando. História de la Inmigración en la Argentina. Buenos Aires, Sudamericana, 2003 e VÁZQUEZ, Alejandro. Emigrantes galegos, transportes e remesas (1830-1930). A Coruña: Fundación Barrié, 2015. 
A variedade de obras publicadas, as explicações acerca dos deslocamentos e de suas causas, os estudos a nível micro e macro, e a utilização de fuentes qualitativas e quantitativas, serviram muitas vezes não somente como referência teórica e metodológica, mas também como ponto de comparação para a análise das semelhanças e diferenças existentes no comportamento migratório. Vale ressaltar que nas últimas décadas tanto a emigração "genérica" 4 como as pesquisas voltadas para as emigrações regionais desenvolveram uma massa crítica de estudos de caso que permitiram a comprensão dos factores macroestruturais e microssociais do fenômeno (particularmente no período da "imigração de massas", entre 1880 e 1930). A maioria desses trabalhos assumiram como axioma -implícita o explícitamente- que o velho dilema das Ciencias Sociais entre a estrutura e a ação, não oferecia resultados satisfatórios para os casos específicos. Somente com a interação entre os fatores explicativos macroestructurais e as redes microssociais poderia se compreender a fundo, certos fluxos migratórios e as características básicas apresentadas pelos mesmos. Assim, as melhores pesquisas operam, atualmente, con una escala de observação que combina a perspectiva macroanalítica com a micro.

$\mathrm{O}$ enfoque estatístico e quantitativo passa a ser empregado em conjunto com as fontes qualitativas, devolvendo aos protagonistas do processo o poder de decisão e de atuação. A explicação do fenômeno migratório também deve ser percebida a partir de uma visão relacional do mundo social. O uso do enfoque de rede social, por exemplo, demonstrou vantagens conceituais e metodológicas para comprender

4 Entre muitas obras, podemos citar, referentes ao caso espanhol que é o mais estudado por nós: ALONSO, Blanca Sánchez. Las causas de la emigración española 1880-1930. Madrid: Alianza editorial, MOYA, José G. Primos y extranjeros. La inmigración española en Buenos Aires, 1850-1930. Buenos Aires: Emecé, 2004 [1998]; NÚÑEZ SEIXAS, Xosé Manoel. Las pátrias ausentes. Estudios sobre historia y memoria de las migraciones ibéricas (1830-1960). Oviedo: Genueve ediciones, 2014, além das referências bibliográficas citadas na nota anterior, Fernando Devoto e Alejandro Vázquez. Em relação às mais obras mais teóricas, MERTON, Robert, Teoría y estructura sociales. México: FCE, 1995 [1964], CARASSOU, Roberto Herrea. La perspectiva teórica en el estudio de las migraciones. México: Siglo XXI editores, 2006. 
os processos sociais pelos quais se difunde e circula a informação ${ }^{5}$. Em relação à integração dos imigrantes, o modelo de Milton M. Gordon, em seu livro Assimilation in American Lyfe: The Role of Race, Religion and National Origins, ampliou o tema com novas perspectivas, na abordagem da "asimilação estructural informal", como podem ser as pautas matrimoniais, residenciais, a participacão em associações voluntárias, o papel das cadeias migratórias, e a movilidade social dos migrantes. Um conjunto de fontes que possibilitou atrativas perspectivas metodológicas que até então haviam sido ignoradas pelos estudos migratórios.

Outra questão levantada no texto de Sylvie Aprile, que pode ocasionar a distinção dos significados de migração e exílios, seria o emprego das teorias pull - push (atração-repulsão), ou seja, as causas da emigração. Segundo Aprile, as situações comuns ou diríamos as migrações espontâneas, onde milhares de sujeitos anônimos formam um fluxo quantitativamente importante em um espaço de tempo, ainda são muitas vezes consideradas como fortuita ou condicionadas pela visão de um acontecimento histórico ligado a um fenômeno de partida (push), mesmo que um contexto económico do país de origem se apresente como fator causal de atração.

Claro está que um movimento de tanta importância como a emigração gerou rapidamente uma perdurável discussão sobre as causas que levaram milhares de pessoas a abandonarem seus países. Essa discussão aconteceu entre os observadores contemporâneos da emigração de massas, polarizados entre os que pensavam que as causas do êxodo deviam buscar-se na miséria e aqueles que afirmavam que o motivo era a busca pela fortuna. A controvérsia era ideológica, entre os que julgavam de maneira otimista o desenvolvimento social, e os pessimistas que recusavam essa justificativa.

A polêmica não foi só retórica ou ideológica. Muitas vezes, por detrás das posições de políticos, publicitários ou jornalistas havia inte-

5 O conceito de redes e de cadeias migratórias muito bem analisadas nas obras já citadas de Fernando Devoto, Alejandro Vázquez e José C. Moya. 
resses concretos de grupos econômicos que calculavam os benefícios e prejuízos que o crescimento da imigração acarretaria. Por exemplo, entre aqueles que eram favoráveis à emigração encontravam-se as companhias de navegação, cujo negócio principal era o transporte de emigrantes e, entre os opositores, estavam os proprietários agrários que temiam o aumento de salários que a diminuição da mão-de-obra no país de origem poderia provocar.

Os chamados pessimistas partiam de matizes conceituais diversas. Entre as mais expressivas, encontram-se a de base econômica (marxista), as estruturais. Essa visão marxista dos processos migratórios baseava-se, inicialmente, na acumulação de capital e no deslocamento da população dos campos para a cidade como fato explicativo da fuga de mão de obra. Dessa forma, milhares de pessoas foram obrigadas a deixar seus lugares de origem, por não terem meios de sobrevivência. Inclusive, uma parte da visão pessimista acredita que a emigração atuara como um obstáculo aos motins revolucionários ou conflitos sociais, impedindo, assim, a luta das sociedades exploradas contra o capitalismo. Permitam-me fazer um breve preâmbulo a respeito dessa visão marxista, utilizando uma célebre frase de um dos grandes intelectuais galegos, considerados um dos pais do nacionalismo galego, exilado na Argentina, Alfonso Castelao: "Os galegos não protestam, emigram". Claro que essa frase tem a ver com o contexto espanhol do início do século XX até o período da Guerra Civil, conjuntura histórica vivida pelo escritor galego. Estamos diante de uma região com um dos maiores índices migratórios da Europa, o Norte da Península Ibérica. Como testemunha ocular daqueles tempos, Castelao descreveu os problemas econômicos e sociais da sua Galiza natal, reafirmou os valores da sua pátria galega, e concebeu a emigração como a ação em meio ao silêncio da sobrevivência do camponês galego.

Seguindo essa linha, Sylvia Aprile discute a obra A Europa em movimento, do historiador Klaus Bade, e a sua hipótese sobre a saída de muitos indivíduos do atual Estado Alemão para a América na véspera da repressão da Primavera dos Povos, no início dos anos 1850. Em seu livro, que trata sobre a migração do final do século XVIII até o presente, ele desenvolveu uma interessante hipótese acerca do du- 
plo significado do termo "emigração válvula», ou seja, abrangendo o sentido socioeconômico e político como motivadores dos deslocamentos. Segundo Klaus Bade, a emigração foi para muitos uma espécie de protesto social mudo, um "voto com os pés", uma forma de luta contra as condições de vida que eles experimentaram em seus países. Em alusão, mais uma vez ao intelectual galego, Afonso Castelao, "não protestar e sim emigrar", foram e são os instrumentos de luta de muitos que deixaram e deixam, referindo-me às migrações presentes, os seus lugares de origem. Como afirma Aprile, deixar o país seria, então, uma necessidade econômica e uma forma de resistência. Ainda seguindo a análise de Aprile, formulamos a seguinte pergunta: devemos tentar dissociar os que partem para fazer fortuna daqueles que querem mudar a sua sociedade? Como exemplo, a autora cita o caso, entre os anos de 1849 e 1851, dos franceses que rumaram em direção à corrida do ouro na Califórnia, estudada por Annick Foucrier, ou as criações das comunas utópicas analisadas por Ronald Creagh. A representação do Novo Mundo é ao mesmo tempo a de um espaço virgem, a da terra prometida e de um espaço democrático. E o historiador deve se confrontar com essas mudanças políticas complexas.

Os fluxos migratórios, envolvendo o ir e vir e as várias sociedades envolvidas no processo, dificilmente podem ser fechados em categorias ou conceitos estritos. É preciso compreender a conjuntura histórica das sociedades de recepção e as fontes que ali se apresentam. Tomemos como exemplo uma das trajetórias estudadas por Sylvie Aprile, a do francês que se exilou nos Estados Unidos, em decorrência do golpe de 1851 de Napoleão III. Marie-Antoine Campdoras parte para os EUA em 1852 e só retorna à França em uma breve viagem feita no ano anterior a sua morte em 1880. Antes de sua partida, Campdoras trabalhava como cirurgião da marinha. Sua aventura começa em 1848 quando embarca em sucessivos navios em missão colonial na África. Essa ocupação (de marinheiros e militares), durante muito tempo dissociada dos movimentos migratórios, será central na experiência de Campdoras na América, considerada como a "terra prometida". Ao chegar em Nova York, o emigrante descobre a familiaridade do local, ao se deparar com uma quantidade significativa de proscritos e emi- 
grantes. Encontra, assim, um meio urbano que ele considera muito similar ao europeu. Depois de passar por Nova Iorque e Louisiana (localidades repletas de imigrantes europeus, sobretudo, franceses) Campdoras se instala no Kansas. Em sua fazenda, ele irá se dedicar ao "mouvement des Granges" de educação de fazendeiros do Sul, um movimento que enfatiza a igualdade entre mulheres e homens, sobre a necessidade de educação social e moral. Segundo Aprile, é fora do campo da história política francesa, pela integração sócio-profissional de Campdoras nos Estados Unidos, que podemos acompanhar sua adaptação à novas formas de politização e a continuidade com os seus compromissos. O emigrante era um republicano convicto, que abraçou novas causas na sociedade de acolhida, a partir de sua experiência vivida na sociedade francesa. A modo comparativo, uma das ocupações mais importantes da emigração galega nos Estados Unidos foi a de marinheiro. No século XIX, muitos galegos embarcavam em navios para comercializar em Cuba e aproveitavam e reemigravam para os Estados Unidos, parando, principalmente em Nova Iorque. Eles contestaram as duras condições de trabalho em que viviam na sociedade de acolhida, organizando-se em sindicatos, de base étnica e industrialista, como a Unión de Fogoneros, Cabos y Engrasadores del Atlántico, assentados nos principais portos da costa leste estadunidense. No caso dos galegos, diferentemente de Campdoras, que já era militante, a luta política foi fruto da experiência adquirida nas sociedades americanas. ${ }^{6}$ Mas, em ambos os casos, a emigração e o engajamento político prevaleceram nas histórias, tanto na individual como na de um coletivo que se fez representar através de um sindicato.

A questão do associativismo étnico, por exemplo, é um campo de estudo que nos remete à problemática da identidade e da integração do emigrante na sociedade de acolhida. Avaliando o caso da chamada emigração mediterrânea (portugueses, italianos e espanhóis) na

6 A autora desse texto é especialista em imigração galega e a pesquisa realizada em Nova York ainda não foi publicada. Há poucos estudos sobre o tema, podemos citar como referência o livro de Alonso, Bieito. Mariñeiros, fogoneiros e anarquistas galegos en New York. Santiago: Edicións a Nosa Terra, 2006. 
América do Sul, em países como Argentina e Brasil, encontramos um movimento circular, de ir e vir, de pessoas e de remessas. Já bastante estudada para alguns grupos, o associativismo inicia-se na segunda metade do século XIX, quando foram criados importantes centros associativos destinados ao assistencialismo, às discussões políticas e ao ócio. Essas associações foram empreendedoras nas sociedades de acolhida, mas também na sociedade de origem. São muitos os casos de envio de remessas para a formação de escolas e desenvolvimento do meio agrícola, nos casos do norte da Península Ibérica, por exemplo. Dessa forma, a emigração torna-se uma via de mão dupla: o emigrante e o exilado constituem-se em elemento de progresso, mas também podem ser tornar um empreendedor na sua terra natal, a partir do capital simbólico e material que a experiência migratória lhe proporcionou. Isso demonstra que a possibilidade do retorno existe tanto no caso do exílio como nas migrações econômicas. Quem escreve sobre o exílio tende a usar o retorno como uma especificidade do exílio e, dessa forma, diferenciá-lo de outras variáveis migratórias. Entretanto, na emigração econômica e principalmente, na espontânea, onde o indivíduo deixa a sua terra através de um planejamento familiar, utilizando-se de seus próprios recursos, o retorno sempre estará presente, mesmo que não se concretize ao longo da experiência migratória. Em base a esses argumentos, Sylvie Aprile esclarece que mais do que dissociar os percursos da emigração é preciso mostrar como os repertórios de ação são mobilizados. Por isso, no caso da trajetória de Marie-Antoine Campdoras sua passagem da condição de exilado para a de imigrante não lhe impede de se dedicar à luta política. Essa observação, segundo Aprile, contraria os comentários de certos republicanos contemporâneos que o acusaram de ter abandonado seus ideais quando deixou a França.

A segunda trajetória masculina analisada no artigo é a de Victor Frond, que vive alguns anos no Brasil e depois retornou à França. Em 1851, ele foi preso na Argélia, conseguindo escapar para Inglaterra, e, em seguida, para Espanha e Portugal. No exílio, ele se dedica a coletar fundos para uma sublevação armada na França até que descobre a sua paixão pela fotografia. Com cartas de recomendação de Victor Hugo ele parte para o Rio de Janeiro onde abrirá um estúdio fotográfico. Com 
o apoio de D. Pedro II ele trará da França outro exilado, Ribeyrolles, com quem realizará a obra "Brasil pitoresco". Depois do armistício em 1859, ele retorna à França e continua com as suas atividades como fotógrafo. Esse retorno de Victor Frond seria, na visão convencional, uma prova da sua condição de exilado e não de imigrante. Porém, segundo Sylvie Aprile, ao contrário de Campdoras, ele não conserva seu engajamento político inicial. Frond, como fotografo, integra, assim como os cartógrafos, geógrafos e, os marinheiros, a chamada experiência dos viajantes - dissociada da história das migrações e exílios.

É necessário superar as questões de quantificação ou de confrontos entre os migrantes e exilados ou entre exilados e militantes dos países de acolhimento. No caso das trajetórias dos dois personagens masculinos, a autora chega à conclusão de que, apesar de fazerem parte do mesmo processo de exílio, como proscritos do Segundo Império, as experiências diferem em razão de seu destino, (um foi para os Estados Unidos, o outro para a América do Sul) e das profissões que exerceram ao longo de suas trajetórias. Isso demonstra, em parte, outra questão importante: a integração na sociedade de recepção. A partir das trajetórias individuais, surgem diversos questionamentos: Qual dos dois franceses continuou sendo um exilado? E qual dos dois se tornou um emigrante? A resposta de Aprile foi que "nem um, nem outro, talvez os dois". Os dois olhares se completam.

A autora argumenta que tanto o historiador como o observador contemporâneo sempre procura distinguir os migrantes e exilados, mesmo quando eles partilham da mesma trajetória. É uma forma de isolar o social do político. A história do exílio e da emigração transatlântica foi durante muito tempo ignorada, segundo Sylvie Aprile. Os exilados encontram-se presos ao seu passado e a sua nostalgia; os migrantes econômicos ao futuro. A afirmação da autora coincide com a de vários estudiosos do tema do exílio e da migrações em geral.

Nos últimos anos, uma das temáticas que mais enriqueceram os estudos migratórios foi a que tratou de indagar conjuntamente os processos migratórios (entendidos em um sentido estrito, como aqueles motivados por fatores sócio-econômicos) e os de exílio (concebidos 
como aqueles deslocamentos forçados, por imperativos principalmente políticos). Dentro do tema do exílio há muitas possibilidades, mas dentro da análise mais geral, aparece a problemática de se o exílio pode ser incluído nos movimentos migratórios ou se obrigatoriamente deve existir uma clara divisão; ou se as migrações somente abrangem os migrantes econômicos ou também se devem incluir os exiliados; ou se os exilados somente pertencem ao grupo de intelectuais e políticos ou podem estar no grupo dos que se sentiram oprimidos por uma situação de violência e miséria e decidiram partir. Nesse caso, vale a pena fazer um breve percurso pela historiografia do século XX e XXI, que tem contribuído de forma substancial, nas últimas décadas, com valiosas pesquisas que entrelaçam o exílio e as migrações.

Um exemplo que podemos destacar é o caso da análise do conjunto da imigração espanhola e do exílio republicano na Argentina. Durante muito tempo, a historiografia sobre o exilio e as migrações peninsulares se desenvolveu como um campo bastante independente. No entanto, desde os inícios do século XXI, surge um significativo número de estudos que vai relacioná-los de forma interdependente. Podemos mencionar a tese de Bárbara Ortuño Martínez El exilio y la emigración española de posguerra en Buenos Aires, 1936-1956, o livro organizado por Nádia de Cristóforis Baixo o signo do franquismo: emigrantes e exiliados galegos na Arxentina ou Alicia Gil, com o livro Inmigración y retorno. Españóis en la ciudad de Mexico (1900-1936) ${ }^{7}$. Nas novas escalas de análises dos problemas teóricos, encontram-se os estudos comparados e a abordagem regional ou local. Bárbara Ortuño, em sua pesquisa, aposta nos enfoques regionais e na questão da escala. Se antes os fluxos migratórios estavam demarcados pelos Estados Nacionais, a nova historiografia trata de analisar as regiões, ou, inclusive, realidades tão

7 ORTUÑO MARTÍNEZ, Bárbara. El exilio y la emigración española de posguerra en Buenos Aires, 1936 1956. Departamento de Humanidades Contemporáneas Facultad de Filosofía y Letras Universidad de Alicante, Alicante, 2010; GIL LÁZARO, Alicia. Inmigración y retorno. Españóis en la ciudad de Mexico (1900-1936). Madrid: Marcial Pons, 2015; DE CRISTÓFORIS, Nádia (coord.). Baixo o signo do franquismo: emigrantes e exiliados galegos na Arxentina. Santiago de Compostela: Sotelo Blanco edicións, 2011, entre outras obras. 
pequenas como as aldeias e munícipios, para melhor compreender as múltiplas relações que se desenvolvem no fenômeno migratório. Por outro lado, a análise qualitativa permite identificar as estratégias de integração e os vínculos estabelecidos com a emigração considerada econômica, além de construir uma nova tipologia dos exiliados, fugindo ao padrão já demarcado pela historiografia pioneira no tema. Sem dúvida, é um novo olhar que vai trazer uma nova postura do historiador e vai involucrar o exílio com as migrações econômicas. $\mathrm{O}$ conceito de exílio se amplia e passa a estar vinculado não somente à figura dos intelectuais e do exílio político, porque conforme afirma Bárbara Ortuño, quando se produz o encontro entre pessoas que viveram circunstâncias similares, em uma mesma faixa etária, e compartilharam experiências, essas experiências atuam como catalizadoras de uma mesma consciência. Seria, então, a memória do exílio, a longa duração que dará origem ao "exílio tardio".

Uma das grandes expoentes da temática do exílio, a professora Silvia Dutrenit, do Instituto Mora, no México, na introdução de seu último livro intitulado Aquellos niños del exilio. Cotidianidades entre el Cono Sury México afirma: “...el exilio, los exílios, y en particular aquellos de la segunda mitad del siglo XX en América Latina, fueron fenómenos colectivos, no de las élites, como lo fueron los ocorridos durante las primeras décadas de esta centúria". Dutrenit fala em "exílios", no plural, nas distintas formas de exílio que surgem nas diferentes conjunturas históricas, mas que permitem a comparação através da experiência da longa duração ${ }^{8}$.

Sylvie Aprile demonstra que a experiência vivida pelos exilados permite que as vítimas, os proscritos, se tornem atores e protagonistas de suas experiências, transformando o exílio em experiências migratórias, modificando as suas formas de vida a partir das relações estabelecidas na sociedade de acolhida. Ou seja: dependendo do lugar, da época ou do grupo migratório os historiadores acentuaram que o grau de assimilação dos recém-chegados foi variável.

8 BIELOUS, Silvia Dutrenit. Aquellos niños del exilio. Cotidianidades entre el cono Sur y Mexico. México: Instiuto Mora, 2015. 
Em suma, através das distintas biografias analisadas no artigo e como os personagens vivenciaram as suas experiências, a autora demonstra que é possível superar os modelos de análise que enclausuraram o exílio. Não é possível, porém, encontrar uma resposta definitiva. É necessário seguir com os modelos comparativos e avançar com os estudos de caso, sem, no entanto, abandonar o que já foi construído no universo macroanalítico dos estudos migratórios.

Recebido: 10/08/2017 - Aprovado: 18/09/2017 